\title{
EPISTEMOLOGI FIKIH DI MEDIA SOSIAL (KONSTRUKSI EPISTEMOLOGIS FATWA MAJELIS ULAMA INDONESIA TENTANG BERMUAMALAH)
}

\section{Qurrota A'yun}

Institut Agama Islam Negeri Pekalongan

E-mail: qurrota.ayun@iainpekalongan.ac.id

\section{Nurul Istiani}

Institut Agama Islam Negeri Pekalongan

E-mail: n_istiani@ymail.com

\begin{tabular}{|c|c|c|}
\hline Received & Revised & Accepted \\
\hline 4 July 2021 & 2 Agustus 2021 & 20 September 2021 \\
\hline
\end{tabular}

\section{FIQH EPISTEMOLOGY IN SOCIAL MEDIA (EPISTEMOLOGY CONSTRUCTION OF FATWA OF INDONESIAN MOESLING SCHOLAR ABOUT MU'AMALAH)}

\begin{abstract}
Absctract
This study intends to explore and identify the epistemological basis of Islamic law in the construction of the Fatwa Majelis Ulama Indonesia (MUI) Nomor 24 Tahun 2017 Tentang Hukum dan Pedoaman Bermuamalah Melalui Media Sosial. This qualitative research is in the form of a literature review with a normative philosophical approach. The analytical theory used is the paradigm of idealism and realism of Islamic law. The results show that the epistemological construction of Islamic law in the fatw MUI a on Law and Guidelines for Bermumalah Through Social Media integrates the tendencies of the idealism and realism paradigm of Islamic law. This can be seen from the various elements that underlie the construction of the epistemological building of the Fatwa MUI. First, universal ethical moral values ('am) which are taken from the theological text basis (nas). Second, the use of the rules of Islamic law (qawaid fiqhiyah) which emphasizes the rules of sadd al-zari'ah (preventive action) and maslahah mursalah (public benefit). Third, the opinion of classical scholars. Fourth, scientific explanations of expert opinions regarding the use of social media. Keywords: epistemology, fatwa MUI, and social media
\end{abstract}

\begin{abstract}
Abstrak
Penelitian ini bermaksud untuk mengeksplorasi dan mengidentifikasi landasan epistemologi hukum Islam dalam konstruksi Fatwa Majelis Ulama Indonesia (MUI) Nomor 24 Tahun 2017 Tentang Hukum dan Pedoaman Bermuamalah Melalui Media Sosial. Penelitiankualitataif ini berupa kajian pustaka dengan pendekatan normatif filosofis. Teori analisis yang digunakan yakni paradigma idealisme dan realisme hukum Islam. Hasil penelitian menunjukan bahwa konstruksi epistemologihukum Islam dalam fatwa MUI tentang Hukum dan Pedoman
\end{abstract}


Bermumalah Melalu Media Sosial mengintegrasikan kecenderungan paradigma idealisme dan realisme hukum Islam. Hal ini dapat dilihat dari berbagai unsur yang melandasi konstruksi bagunan epistemologi Fatwa MUI tersebut. Pertama, nilai moral etik universal(' $a m$ ) yang diambil dari landasan teks teologis (nas). Kedua,penggunaan kaidahkaidah hukum Islam (qawaid fiqhiyah) yang menekankan pada kaidahsadd al-zari'ah (tindakan preventif) dan maslahah mursalah (kemashlahatan umum).Ketiga, pendapat ulama klasik.Keempat, penjelasan ilmuan pendapat para ahli terkait penggunaan media sosial.

Kata kunci: epistemologi, fatwa MUI, dan media social.

\section{Pendahuluan}

Tidak dapat dibantah perkembangan dunia teknologi yang dinamis berperan besar dalam perubahan pola dan tatanan kehidupan masyarakat modern dewasa ini. Namun banyaknya penggunaan teknologi tidak senantiasa dibarengi dengan sikap dan pengetahuan literasi yang baik. Sebagai contoh keberadaan aplikasi media sosial (medsos) berbasis digital sering dijadikan sebagai media instan tanpa melihat implikasi negatif dari penggunaannya. ${ }^{1}$ Hal demikian menyebabkan banyak ditemukan pelbagai problem interaksi sosial yang dapat ditemukan dalam aktifitas dunia medsos.$^{2} \mathrm{Hal}$ itu disebabkan medsos sebagai medium yang sering digunakan untuk aktifitas kebebasan berekspresi individu privat dalam konteks ruang publik tidak diikuti oleh pelbagai norma atau etika sosial para penggunanya. ${ }^{3}$

Beberapa problem interaksi sosial yang seringkali ditemukan di dunia medsos, antara lain penyampaian informasi dan silang pendapat dengan tanpa dibarengi sikap penghormatan, toleransidan empati antar pengguna medsos. ${ }^{4}$ Banyak juga ditemukan pelbagai berita bohong yang disebar oleh para pengguna medsos. ${ }^{5}$ Bahkan ujaran kebencian, seperti penghinaan, menghasut, provokasi politik, pencemaran nama baik dan lain sebagainya. ${ }^{6}$ Tidak berhenti di situ, problem penggunaan medsos sebagai medium interaksi sosial jugamenyisahkan problem sekaligus tantangan baru dalam dunia aktifitas syiar keagamaan. ${ }^{7}$ Berbagai bentuk problem dalam penggunaan medsos sebagai medium interaksi sosial tersebut

${ }^{1}$ Suyati Suyati, "Dampak Media Sosial Terhadap Konflik Di Masyarakat," JURNAL PETIK 7, no. 1 (2021): 30.

${ }^{2}$ Waseem Akram and Rekesh Kumar, "A Study on Positive and Negative Effects of Social Media on Society," International Journal of Computer Sciences and Engineering 5, no. 10 (2017): 347.

${ }^{3}$ Fahmi Anwar, "Perubahan Dan Permasalahan Media Sosial," Jurnal Muara Ilmu Sosial, Humaniora, Dan Seni 1, no. 1 (2017): 137.

${ }^{4}$ Uud Wahyudin, "Kismiyati El Karimah. 2016.'Etika Komunikasi Di Media Sosial,”, in Prosiding Seminar Nasional Komunikasi, n.d., 216.

${ }^{5} J u d i t h a$ Christiany, "Interaksi Komunikasi Hoax Di Media Sosial Serta Antisipasinya," Jurnal Pekommas 3, no. 1 (2018): 31-44.

${ }^{6}$ Dian Junita Ningrum, Suryadi Suryadi, and Dian Eka Chandra Wardhana, "Kajian Ujaran Kebencian Di Media Sosial," Jurnal Ilmiah Korpus 2, no. 3 (2018): 241.

${ }^{7}$ Mastori Mastori and Athoillah Islamy, "Menggagas Etika Dakwah Di Ruang Media Sosial," KOMUNIKASIA: Journal of Islamic Communication and Broadcasting 1, no. 1 (2021): 2. 
meniscayakan pentingnya keberadaan normasosial, agama, bahkan norma agama yang mengaturnya. ${ }^{8}$

Merespons berbagai problem empirik penggunaan medsos di atas, Majelis Ulama Indonesia (MUI)menetapkan Fatwa MUI Nomor 24 Tahun 2017 tentang Hukum dan Pedoman Bermuamalah Melalui Media Sosial. Namun penting diketahui bahwa sebelum adanya Fatwa MUI tersebut, pemerintah Indonesiatelah mengesahkan Undang-Undang Republik Indonesia Nomor 11 Tahun 2008 tentang Informasi dan Transaski Elektronik (ITE). ${ }^{9}$ Meski telah terdapat seperangkat norma hukum nasional dan juga fatwa MUI yang mengatur penggunaan medsos. Akan tetapi angka kasus pelanggaran dalam hal pemanfaatan medsos di Indonesia masih relatif tinggi. Pada tahun 2020, kasus pidana terjadi kenaikan berkaitan dengan aktifitas penggunaan medsos. Dalam tahun tersebut telah terdapat sekitar 59 kasus dari jumlah angka tahun sebelumnya (2019) yang mencapai 24 kasus. $^{10}$

Berpijak pada kegelisahan akademik di atas, penelitian ini bermaksud untuk mengeksplorasi dan mengidentifikasi landasan epistemologi hukum Islam dalam konstruksi fatwa MUI No.24 Tahun 2017 Tentang Hukum dan Pedoman Bermuamalah Melalui Media Sosial. ${ }^{11}$ Penelitian ini perlu dilakukan, agar dapat ditemukan kerangka paradigmatik dalam konstruksi bangunan norma fatwa MUI tersebut.Apakah paradima yang digunakan lebih bersifat idealistik-deduktif normatif, yakni mengacu pada landasan teologis ajaran Islam?atau lebih bersifat realistik induktif-empiris, yakni mengacu pada fenomena problem dan kebutuhan empirik dalam kehidupan sosial.

Penulis menyadari pasca diterbitkannya Fatwa MUI tentang hokum dan pedoman bermuamalah di medsos terdapat beberap penelitian yang mengkajinya dengan ragam fokus kajian dan perspektif masing-masing. Namun dalam konteks ini, penulis akan menguraikan berbagai penelitian sebelumnya yang memiliki relevansi dengan penelitian penulis ini, antara lain sebagai berikut. Ikhwanuddin Harahap (2017) menuturkan bahwa pertimbangan kemaslahatan (al-maslahah) yang menjadi orientasi hukum Islammerupakan bagian penting dari pertimbangan Majelis Ulama Indonesia (MUI) dalam mengeluarkan fatwa MUI Nomor 24 tahun 2017 tentang Hukum dan Pedoman Bermuamalah melalui Media Sosial. ${ }^{12}$ Penelitian Ikhwanuddin ini memiliki relevansi dengan penelitian penulis, akan tetapi fokus dan hasil penelitian Ikhwanuddin tersebut masih parsial, yakni belum berupaya

\footnotetext{
${ }^{8}$ Athoillah Islamy, "Paradigma Sosial Profetik Dalam Bermuamalah Di Media Sosial," Tadbir: Jurnal Manajemen Dakwah FDIK IAIN Padangsidimpuan 3, no. 1 (2021): 86.

${ }^{9}$ Radita Setiawan and Muhammad Okky Arista, "Efektivitas Undang-Undang Informasi Dan Transaksi Elektronik Di Indonesia Dalam Aspek Hukum Pidana," Jurnal Hukum Pidana Dan Penanggulangan Kejahatan 2, no. 2 (2013): 139.

10“Perludem. 19 Mei 2020. Https://Perludem.Org/Wp-Conten - Penelusuran Google," accessed August 23, 2020,.

${ }^{11}$ Komisi Fatwa, "Fatwa Majelis Ulama Indonesia (MUI) Nomor 24 Tahun 2017 Tentang Hukum Dan Pedoman Bermuamalah Melalui Media Sosial" (n.d.), 13, accessed August 14, 2021.

${ }^{12}$ Ikhwanuddin Harahap, "Pendekatan Al-Mașlaḥah Dalam Fatwa Majelis Ulama Indonesia (Mui) Nomor 24 Tahun 2017 Tentang Hukum Dan Pedoman Bermuamalah Melalui Media Sosial," Yurisprudentia: Jurnal Hukum Ekonomi 3, no. 1 (2017): 64.
} 
menggali berbagai unsur yang menjadi landasan epistemologis hokum Islam dalam Fatwa MUI tersebut. Masih terbatas pada temuan unsur maslahat.

Berikutnya, Subehan Khalik (2018) mengatakan norma fatwa MUI terkait pedoman bermuamalah di media sosial belum mengatur penggunaan media sosial dalam konteks transaksi ekonomi. Padahal norma tersebut sangat dibutuhkan. Mengingat di era digital saat ini, banyak sekalai amasyarakat menggunakan medsos sebagai medium transaksi bisnis secara online (ecomerce). Di mana banyak terjadi kasus pelanggaran dalam transaksi online tersebut. ${ }^{13}$ Berbeda dengan penelitian Subehan tersebut, penelitian ini lebih pada aspek paradigmatik yang dijadikan sebagai basis epitemologi hukum Islam dalam konstruksi norma Fatwa MUI tentang Hukum dan Pedoman Bermuamalah di medsos.

Selanjutnya, Athoillah Islamy (2019) menyimpulkan bahwa fatwa ketentuan hukum MUI yang membatasi kebebasan berinteraksi sosial melalui media sosial merupakan ketentuan hukum dalam mewujudkan kemaslahatan individu (almaslahatal-khassah) dan masyarakat (al-maslahat al-ammah). ${ }^{14}$ Sebagaimana penelitian Ikwanuddin Harahap, penelitian Athoillah ini masih parsial dalam menggali landasan epistemologis dalam konstruksi fatwa MUI tentang Hukumdan Pedoman bermuamalah di media sosial, yakni masih sebatas dalil maslahah yang ditemukan.

Berpijak dari berbagai penelitian yang relevan di atas, tidak ditemukan penelitian yang fokus mengkaji landasan epistemologis konstruksi fatwa MUI tentang Hukum dan Pedoman Bermuamalah di media sosial dengan pendekatan idealisme dan realisme hukum Islam.Hal inilah yang menjadi nilai distingtif penelitian ini dari ragam penelitian sebelumnya.

\section{Metode Penelitian}

Jenis penelitian kualitatif iniberupastudi pustaka (library research). ${ }^{15}$ Sumber data primeryang digunakan, yaknidokumen fatwa Majelis Ulama Indonesia (MU)Fatwa Majelis Ulama Indonesia (MUI) Nomor 24 Tahun 2017 Tentang Hukum dan Pedoman Bermuamalah Melalui Media Sosial. Sedangkan data sekunder berupa berbagai penelitian ilmiah yangrelevans dengan inti pembahsan dalam penelitian ini.Pendekatan penelitian ini, yakni pendekatan normatif filosofis. Teori analisis yang digunakan yakni paradigm idealisme dan realisme hokum Islam.Pada aplikasinya, teori tersebut akan digunakan dalam mengeksplorasi sekaligus mengidentifikasi berbagai unsur yang menjadi landasan argumen dalam konstruksi norma Fatwa MUI tentang Hukum dan Pedoman Bermuamalah di medsos Sementara itu, sifat pendekatan penelitian ini, yakni deskriptif-analitik. Akan

\footnotetext{
${ }^{13}$ Subehan Khalik Umar, "Studi Kritis Terhadap Respon Majelis Ulama Indonesia (Mui) Tentang Pemanfaatan Media Sosial Dalam Bermuamalah," Al Daulah: Jurnal Hukum Pidana Dan Ketatanegaraan 7, no. 1 (2018): 40.

${ }^{14}$ Athoillah Islamy, "Fatwa About Social Interaction On Social Media In The Paradigm Of Islamic Legal Philosophy," Al-Mishbah: Jurnal Ilmu Dakwah Dan Komunikasi 15, no. 2 (2020): 163.

${ }^{15}$ Lexy J. Moleong, "Metodologi Penelitian Kualitatif Edisi Revisi," Bandung: PT Remaja Rosdakarya 103 (2007): 6.
} 
tetapijuga bersifat preskriptif dalam memberikan saran yang mengacu pada analisis pembahasan inti.

\section{Hasil dan Pembahasan \\ Idealisme dan Realisme Pemikiran Hukum Islam}

Jika epistemologi pemikiran Barat berpijak dari dua basis paradigma rasionalisme dan empirisme. Lain halnya dengan pemikiran Islam. Dalam paradigma Islam, untuk mendapatkan ilmu pengetahuan atau sebuah pemikiran Islambukan hanya bersandar pada rasionalisme dan empirisme, melainkan juga berpijak pada intuisi dan nas teologis (wahyu Tuhan). Atas dasar inilah tidak mengehrankan ketika epistemologi pemikiran Islam memposisikan titik tolak Islam sebagai subjek dalam mengkaji filsafat pengetahuan, maka sekaligus disatu epistemologi Islam bermuara pada wahyu Allah. Dengan kata lain,eksistensi wahyu menjadi sumber pengetahuan dan sumber segala validasi kebenaran. Oleh sebab itu, sejatinya uapaya berfikir rasional dan empirik menjadi bagian sah dari epistemologi Islam, akan tetapi salah satu karakter fundamental dari epistemologi Islam dan yang menjadi distingsi dengan epistemologi Barat (sekular), yakni adalah internalisasi nilai-nilai normatif ajaran Islam sebagai bagian dari prinsip sekaligus tolak ukur validitasnya. Oleh sebab itulah, landasan nas teologis dalam epsitemologi Islam menduduki peran sentral dalam memberi inspirasi, membimbing, serta menentukan arah orientasi kajian sains Islam. ${ }^{16}$

Eksistensi idealisme dan realisme dalam diskursus filsafat Yunani dapat dijadikan sebagai paradigma dalam menjelaskan kontestasi antara idealisme dan realisme dalam berbagai kajian ilmu keislaman, tidak terkecuali dalam kajian pemikiran hukum Islam. ${ }^{17}$ Keberadaan idealisme dalam pemikiran hukumIslam tidak dapat dilepaskan dari pengaruh kuat filsafat Yunani. ${ }^{18}$ Paradigmaidealisme ini berpengaruh pada pemikiranhukum Islam yang senantiasa berupayauntuk menerima wahyu sebagai substansi dan essensi. Implikasi dari paradigm tersebut meniscayakan kecenderungan produk pemikiran hukum Islam bersifat deduktifidealistik dengan mengabaikan fakta empirik di lapangan kehidupan manusia.Karakter pemikiran demikiandapat dijumpaipada tradisi epistémologi

\footnotetext{
${ }^{16}$ Wira Hadikusuma, "Epistemologi Bayani, Irfani Dan Burhani Al-Jabiri Dan Relevansinya Bagi Studi Agama Untuk Resolusi Konflik Dan Peacebuilding," Jurnal Ilmiah Syi'ar 18, no. 1 (2018): 2.

${ }^{17}$ Ilyas Supena, "Konstruksi Epistemologi Fikih Pandemik: Analisis Fatwa-Fatwa MUI," A LManāhij: Jurnal Kajian Hukum Islam 15, no. 1 (2021): 126.

${ }^{18} \mathrm{Di}$ antara pandangan umum atas pengaruh filsafat Yunani terhadap metodologi hokum Islam, yakni tentang usnur dalam metode Qiyas (analogy hokum Islam). Terdapat terdapatnya unsur silogisme logika Aristoteles dalam metode tersebut semenjak masa al-Shafi'i (150-204 H/ 767820 M). Hal demikian pada akhirnya, menjadikan konsep qiyas kurang dinamis, karena senantiasa mengikuti premis mayor yang diisimpulkan dari nas. Logika tersebut juga menjadikan qiyas bersifat ketat dan kontraproduktif, karena mengikuti prinsip sillogisme. Padahal seyogyanya qiyas merupakan sebuah konsep penalaran hukum yang dinamis, liberal, dan akomodatif dalam menyikapli problem perkembangan hukum di masyarakat yang ada. Athoillah Islamy, "Pemikiran Hukum Islam Nurcholish Madjid" (Semarang, Disertasi Pascasarjana Universitas Islam Negeri Walisongo, 2021), 197.
} 
bayanîyang memekankanproses mendapatkan pengetahuan (pemikiran) Islam mengacu pada landasan teks (wahyu). ${ }^{19}$

Menurut Muhammad Abed Al-Jabiri,bayani merupakan metode pemikiran khas Arab yang menekankan pada otoritas teks (nash), baik secara langsung dengan memahaminya sebagai pengetahuan yang sudah jadi dan dapat secara otomatis diaplikasikan, maupun secara tidak langsung dengan memahaminya secara tekstual tanpa adanya intervensi penalaran (tafsir). Dengan kata lain, posisi rasionalitas (akal) manusia dalam epistemologi bayani tidak memiliki kemampuan memberikan pengetahuan tanpa adanya sandaran pada landasan teks (wahyu). Dengan demikian, sumber validitas pemikiran (pengetahuan) dalam epistemologi bayani, yakni adalah landasan teks (nash), baik al-Quran maupun Hadits. ${ }^{20}$ Implikasi paradigmatiknya, yaknisemakin dekat realitas dengan landasan teks wahyu, maka semakin kuat validitas kebenarannya.Implikasi paradigmatiknya, gagasanidealismepemikiran hukum Islam seringkali kurang bahkan tidakbersinggungan dengan realitas pengalaman empirik serta kebutuhanmasyarakat. ${ }^{21}$

Berbeda dengan idealisme dalam pemikiran hukum Islam, kecenderungan paradigma realisme dalam pemikiran hukum Islam juga dapat ditemukan dalam beberapa tokoh intelektual muslim yang lebih menekankan pada epistemologiburhani sebagai basis paradigmatiknya. ${ }^{22}$ Epsitemologi burhani menekankandiri manusia kepada kompetensi rasionalitas akalnya dengan mengggunakan berbagai dalil logika.Oleh karena itu, keberadaan dalil-dalilagama dalam epistemology burhanidapat diakui selama paralelatau tidak bertentangan dengan logika manusia.Sedangkan burhani menghasilkan pengetahuan melalui ragam prinsip logika atas pengetahuan sebelumnya yang sudah diyakini validitas kebenarannya. ${ }^{23}$

Idealime pemikiran hukum Islam mendapat pijakan kuat pada sosok Ibnu Rusyd yang berupaya mengikut pemikiran rasionalisme dan melakukan pembelaan terhadap argumen kausalitas sebagaimana pada sistem filsafat Aristoteles. ${ }^{24}$ Dari model paradigma inilah lahir penalaran demonstratif dengan mengambil jalan pengujian induktif. ${ }^{25}$ Eksistensi penalaran demonstratif ini digunakan Ibnu Rusyd tidak hanya untuk memaknai rasionalitas filsafat, melainkan rasionalitas agama. Seperti halnya Ibnu Hazm, cara Ibnu Rusyd berpedoman pada arti tekstualitas

\footnotetext{
${ }^{19}$ Supena, "Konstruksi Epistemologi Fikih Pandemik: Analisis Fatwa-Fatwa MUI," 126-27.

${ }^{20}$ Hadikusuma, "Epistemologi Bayani, Irfani Dan Burhani Al-Jabiri Dan Relevansinya Bagi Studi Agama Untuk Resolusi Konflik Dan Peacebuilding," 3-4.

${ }^{21}$ Supena, "Konstruksi Epistemologi Fikih Pandemik: Analisis Fatwa-Fatwa MUI," 126-27.

${ }^{22}$ Supena, 127.

${ }^{23}$ Hadikusuma, "Epistemologi Bayani, Irfani Dan Burhani Al-Jabiri Dan Relevansinya Bagi Studi Agama Untuk Resolusi Konflik Dan Peacebuilding," 11-12.

${ }^{24}$ Setidaknya terdapat dua kontribusi besar Ibnu Rusyd dalam perkembangan filsafat Islam.Pertama,pandangannya tentang keabsahan berragam jalur untuk menemukan kebenaran yang sama. Semua jalur yang dipakai sama-sama bisa diterima, dan didasarkan pada teori makna yang sangat rasional dan kaya pemikiran. Kedua, mengintegrasikan filsafat dan agama,Muhammad Jayus and Muhammad Irham, "Fiqh Rasional Dan Tekstual Ibn Rusyd Serta Implikasinya Dalam Hukum Islam Modern," El-Izdiwaj: Indonesian Journal of Civil and Islamic Family Law, 1, no. 1 (2020): 7.

${ }^{25}$ Supena, "Konstruksi Epistemologi Fikih Pandemik: Analisis Fatwa-Fatwa MUI," 127.
} 
teks(żāhiriyyah) dan tidak mengacu pada interpretasi batin (ta'wīl). Untuk memaknai sebuah teks, Ibnu Rusyd menggunakan cara pengujian induktif terhadap semua teks al-Qur'an. Pengujian induktif ini sejatinya membawa Ibnu Rusyd dalammempertimbangkan "maksud dari teks wahyu" (maqāșid al-syārii) untuk membantu dalam memaknai teks al-Qur'an. Dengan cara ini, Ibnu Rusyd berhasil menetapkan bahwa rasionalitas filsafat dan rasionalitas agama saling bersimbiosis. Rasionalitas filsafat dilandaskan pada kesesuaian alam dan berpedoman pada kausalitas. Selain itu, rasionalitas agama dilandaskan atas dasar tujuan yang dilakukanoleh pembuat hukum (maqāșid al-syāri) sehingga berujung pada cara untuk membawa manusia pada nilai-nilai kebajikan yang berkesinambungan. Hal demikian dapat diartikan bahwa gagasanmaqāhid al-syār'i dalam ranah ilmu agama sebanding dengan gagasan hukum kausalitas di ranah filsafat. Pada kajian hukum Islam, pandangan realisme mengakui bahwa hukum islam harus mengikuti realitas dan mampu memberikan saran jika terjadi problem di masyarakat. Aliran realisme menyatakan bahwa realitas sosial sejatinya mampu menjadikan dasar terbentuknya suatu hukum. Para penganut aliran ini menganggap campur tangan manusia tidak terlepas dari adanya proses pembentukan hukum Islam baik dengan jalan ijtihad maupun istinbāṭ al-ahkām yang berlandaskan pada prinsip umum al-Quran. Prinsipumum tersebut dapat diartikan sebagai etika Islam dan berpotensi mewujudkan berbagai interpretasi yang disesuaikan dengan situasi dan kondisi. ${ }^{26}$

Aliran realisme ini mempunyaipokok historis dalam sejarah teori keilmuan Islam. Pertama, asbāb al-nuzūl (sebab diturunkannya al-Quran). Secara etimologi, asbāb al_nuzūl diartikan sebagai suatu peristiwa yang ditanyakan oleh Sahabat terkait sebab musabab al-Qur'an diturunkan. Sedangkan secara terminologi, asbāb alnuzūldiartikan sebagaiasal muasal sejarah diturunkannya wahyu yang bertujuan untuk memberi penjelasan terhadap bagian-bagian al-Qur'an serta memberikancaradalam memahami perintah Tuhan. Hal tersebut dikarenakan bahwa al-Qur'an merupakan jawabanTuhan melalui ingatan dan pikiran Nabi terhadapkondisi sosial dan moral masyarakat Arab pada masa Nabi. Kedua, maqasdhid syariah (tujuan pensyariatan) berupa kabaikan dan kemanfatan pada setiap perintah yang diberikan Allah (mașlahah) serta menjauhkan diri dari mara bahaya (sad al-żarı̄ah). Hukum yang tidak memiliki tujuan kemashlahatan dapat menjadikan hukum tersebut kehilangan legitimasi sosial dalam masyarakat. Orientasi kontekstual-humanistik ini dapat dijumpaipada ayat al-Quran secara holistik, bukan parsial. Ketiga, 'illat Hukum (Ratio Legis) Al-Quran. Menurut pandangan tradisional, 'illat al-hukm merupakan titikkesamaan prinsip yang antarahukum persoalan pokok (așl) dalam al-Quran maupun Sunnah dengan persoalan cabang(furū'). Atasa dasar titik kesamaan tersebut hukum yang berlaku pada așl juga berlaku bagi furū. ${ }^{27}$

Pada penelitian ini, konsep idealisme dan realisme pemikiran hukum Islam di atas akan dijadikan sebagai teori analisis dalam mengeksplorasisekaligus mengidentifikasi konstruksi epistemologis fatwa MUI tentang hukum dan pedoman bermuamalah di media sosial.

\footnotetext{
${ }^{26}$ Supena, $127-28$.

${ }^{27}$ Supena, 128.
} 


\section{Eksistensi Media Sosial : Media Interaksi Sosial (Muamalah)}

Perkembangan dunia teknologi komunikasi dan informasi yang sangat signifikan telah menghadirkan ragam inovasi dalam memberikan kemudahan bagi kehidupan masyarakat modernl. Kehadiran media sosial (medsos) misalnya. Medsos telah menjadi media interaksi sosial, baik dalam konteks komunikasi maupun informasi yang banyak digandrungi oleh masyarakat modern. ${ }^{28}$ Keberadaan medsos telah berperan besar pada segala aspek kehidupan masyarakat modern, baik di bidang pendidikan, ekonomi, politik, sosial budaya maupun keagamaan.Atas dasar inilah, tidak mengherankanjika medsos telah menjadi tren globalisasi dalam bidang media komunikasi dan informasi anyak digunakan masyarakat di berbagai penjuru negara, tidak terkeculai Indonesia. ${ }^{29}$

Menurut Rulli Nasrullah, terdapat dua karakter yang menjadi kunggulan medsos dari media komunikasi konvensional. Pertama, medsos menggunakan jejaring internet yang dapat menjadikanya sebagai media komunikasi dan informasi dengan jangkauan luas, yakni tidak dibatasi jarak, waktu maupun tempat. Kedua, medsos dapat menjadi media komunikasi interaktifyang menyediakan pelbagai bentuk layanan penggunanya untuk dapat saling berkomunikasi secara interaktif, intens bahkan dapatdengan bertatap muka. ${ }^{30}$ Oleh karena itu, dapat dikatakan bahwa komunikasi melalui medsos sudah tidak terbatas lagi pada relasi fisik, melainkan juga relasi tatap muka.

Selanjutnya,penting diketahui keberadaan medsos dalam konteks media interaksi sosial telah dapat menggeser peran media massa konvensional dalam dunia informasi. ${ }^{31}$ Pada konteks inilah, Shiefti Dyah Alyusi menuturkan terdapat lima karakteristik sebuah masyarakat informasi. Pertama,kondisi masyarakat yang dapat memanfaatkan media massa dan komunikasi global. Kedua,kondisi masyarakat yang memiliki kesadaran atas pentingya sebuah informasi dan adaya upaya untuk mendapatkannya. Ketiga,kondisi masyarakat yang menjadikan eksistensi informasi sebagai sebuah komoditas ekonomi. Keempat,kondisi masyarakat yang berinteraksi sosial dalam sistem masyarakat global. Kelima,kondisi masyarakat yang dapat mengakses pelbagai bentuk informasi secara cepat. ${ }^{32}$

Berdasarkan penjelasan di atas, dapat disimpulkan bahwa medsos berkontribusi besar dalam terbentuknya tatanan masyarakat informasi. Oleh sebab itu, tidaklah mengherankan jika eksistensi medsos sebagai media interaksi sosial telah menawarkan paradigma dan cara baru dunia komunikasi maupun informasi dalam aktifitas kehidupan masyarakat modern.

\footnotetext{
${ }^{28}$ Maya Sandra Rosita Dewi, "Islam Dan Etika Bermedia (Kajian Etika Komunikasi Netizen Di Media Sosial Instagram Dalam Perspektif Islam)," Research Fair Unisri 3, no. 1 (2019): 139-40.

${ }^{29}$ Nurul Istiani and Athoillah Islamy, "Fikih Media Sosial Di Indonesia (Studi Analisis Falsafah Hukum Islam Dalam Kode Etik NetizMu Muhammadiyah)," ASY SYAR'IYYAH: JURNAL ILMU SYARI'AH DAN PERBANKAN ISLAM 5, no. 2 (2020): 203-4.

${ }^{30}$ Rulli Nasrullah, Teori Dan Riset Media Siber (Cybermedia) (Kencana, 2016), 75-78.

${ }^{31}$ Fauzi Syarief, "Pemanfaatan Media Sosial Dalam Proses Pembentukan Opini Publik (Analisa Wacana Twitter Sby)," Jurnal Komunikasi 8, no. 3 (2017): 264.

${ }^{32}$ Shiefti Dyah Alyusi, Media sosial : Interaksi, Identitas dan Modal Sosial (Prenada Media, 2019), 25-26.
} 


\section{Konstruksi Epsitemologis Hukum Islam dalam Fatwa Majelis Ulama Indonesia Tentang Hukum dan PedomanBermuamalah Melalui Media Sosial}

Sebagai ajaran agama wahyu terakhir, Islam memuat beragam ajaran universalnyayang melintasi segala ruang dan waktu.Dalam hal ini, pentng disadari dan diketahui bahwa sejatinya universalisme Islam bukan terletak pada aspek kedetailan ajarannya, akan tetapi terdapat padaberbagai ajaran universal yang ditekankannya, seperti nilai keadilan, kemashlahatan, dan karakter fleksibilitasnya dalam meresponsdinamika perkembangan kehidupan sosial umat dengan berbagai problem yang ada. ${ }^{33}$

Ssebagai lembaga yang mempunyaiyang memiliki kompetensi dan otoritas dalam mengeluarkan fatwa sosial keagamaan Islam di Indoensia sudah pastinya konstruksi fatwa MUI tidak sekedar bercorak legal formalistik, melainkan memuat dimensi epsitemologis yang menjadi landasan paradigmatic dalam konstruksi norma fatwannya. Pada sub bab pembahasan initi ini, akan diuraikan analisis epistemologis hokum Islam terhadap konstruksi fatwa MUI tentang Hukum dan Pedoman Bermuamalah Melalui Media Sosial. ${ }^{34}$ Berdasarkan analisis penulis landasan (dalil) dalam Fatwa MUI tentang Hukum dan Pedoman Bermuamalah Melalui Media Sosial dapat dipetakan dalam empat aspek epistemologis.Uraian lebih lanjut, sebagai berikut.

Pertama,dalil nas(al-Quran dan Hadis).Pada konteks ini, dalil nas yang dijadikan sebagai landasan argumen Fatwa MUIcenderung menggunakanberbagai ayat yang memuatpesanklausula umum (ām) dari pada kalusula khusus (khāsh). Hal demikian dapat dilihat dalam berbagai ayat yangdijadikan sebagai dalil Fatwa MUI tersebut, antara lain, (1) QS. Al-Hujurat ayat 6 yang artinya : "Hai orang-orang yang beriman, jika datang kepadamu orang fasik membawa suatu berita, maka periksalah dengan teliti, agar kamu tidak menimpakan suatu musibah kepada suatu kaum tanpa mengetahui keadaannya yang menyebabkan kamu menyesal atas perbuatanmu itu." (2) QS. An-Nur ayat 16 yang artinya "Dan mengapa kamu tidak berkata, diwaktu mendengar berita bohong itu: "Sekali-kali tidaklah pantas bagi kita memperkatakan ini, Maha Suci Engkau (Ya Tuhan kami), ini adalah dusta yang besar."(3) QS. AlHumazah ayat 1 yang artinya "Celakaanlah bagi setiap pengumpat lagi pencela." (4) QS Al-Maidah ayat 8 yang artinya "Hai orang-orang yang beriman, hendaklah kamu jadi orang-orang yang selalu menegakkan (kebenaran) karena Allah, menjadi saksi dengan adil. Dan janganlah sekali-kali kebencianmu terhadap sesuatu kaum, mendorong kamu untuk berlaku tidak adil. Berlaku adillah, karena adil itu lebih dekat kepada takwa. Dan bertakwalah kepada Allah, sesungguhnya Allah Maha Mengetahui apa yang kamu kerjakan."(5) QS Al-Azhab ayat 58 yang artinya "Dan orang-orang yang menyakiti orang-orang yang mukmin dan mukminat tanpa kesalahan yang mereka perbuat, maka sesungguhnya mereka telah memikul kebohongan dan dosa yang nyata.”

${ }^{33}$ Athoillah Islamy, "Landasan Filosofis Dan Corak Pendekatan Abdurrahman Wahid Tentang Implementasi Hukum Islam Di Indonesia," Al-Adalah: Jurnal Hukum Dan Politik Islam 6, no. 1 (2021): 61 .

${ }^{34}$ Fatwa, Fatwa Majelis Ulama Indonesia (MUI) Nomor 24 Tahun 2017 Tentang Hukum dan Pedoman Bermuamalah Melalui Media Sosial. 
Sementara berbagai Hadis yang digunakan antara lain (1) "Barangsiapa yang beriman kepada Allah dan hari akhir maka hendaknya ia berkata yang baik atau diam." (HR. Bukhari dan Muslim).(2) "Sesama orang muslim itu bersaudara. Tidak boleh berbuat zalim dan aniaya kepadanya. Barang siapa yang membantu memenuhi kebutuhan saudaranya niscaya Allah SWT akan memenuhi kebutuhannya dan barang siapa yang membantu meringankan kesulitan saudaranya niscaya Allah SWT akan meringankan kesulitannya di hari kiamat kelak. Dan barang siapa menutupi aib seorang muslim niscaya Allah SWT akan menutupi aibnya di hari kiamat."(HR. alBukhari). (3)“Orang muslim adalah orang yang mampu membuat rasa aman orang lain, dengan menjaga lisan dan tangannya. Sedang orang yang hijrah adalah seseorang yang berpindah guna menjauhi hal_hal yang dilarang oleh Allah SWT." (HR. al-Bukhari dan Muslim) (4) "Jauhilah berprasangka, karena sesungguhnya prasangka adalah pembicaraan yang paling dusta. Janganlah kalian mencari-cari kesalahan orang lain, jangan saling menyombongkan diri (dalam hal duniawi), jangan saling iri, saling membenci satu dengan yang lain, dan saling berpaling muka satu dengan yang lain. Jadilah kalian para hamba Allah bersaudara."(HR. al-Bukhari). ${ }^{35}$

Melihat berbagai dalil nas yang dijadikan sebagai landasan argument Fatwa MUI di atas, maka dapat dikatakan MUI lebih mengedepankan berbagai ayat yang bersifat umum (am)dari pada ayat yang bersifat khusus (khash) dalam landasan epistemologis konstuksi norma Fatwa trkait muamalah di medsos. Penting diketahui kembali, bahwa keberadaan dalil ayat (nas)dalam konteks basis pensyariatan hukum memuatmemiliki karakter cakupan makna. Dengan kata lain, memiliki sasaran kepada siapa pensyariatansebuah hukum dimaksudkan. Dalam konteks inilah, terdapat sejumlah karakteristik yang menjadikan maksud ayat hukum bersifat umum, yaknimeliputi semua individu ataurelevandengansegala kondisi.Di satu sisi, juga terdapat sejumlah karakteristik yang menjadikan maksud ayat hukumterbatas dan bersifat khusus. ${ }^{36}$

Fazlur Rahman sebagaimana yang dikutip oleh Ilyas Supena, menuturkan berbagai prinsip umum dalam al-Quran ('âm) menjadi prinsip fundamental dan senantiasa relevan untuk diaplikasikan. Oleh sebab itu,upaya pemahaman atas dimensi teks dan dimensi sosial merupakan dua hal yang tidak dapat diabaikan. Keduannya akan menjadi kualifikasi mutlak dalam upaya menangkap pesan ayat alQur'anyang bersifat essensial-substansial-fundamental-universal sekaligus membedakan dari yang bersifat lokal-regional-partikular. Atas dasar inilah, maka tidaklah mengherankan jika problem hermeneutis dalam berbagai ilmu keislaman, yakni tentang merumuskan hubungan dialogis antara universalitas dan partikularitas pesan ayat al-Qur'an.Selain itu, juga terkait bagaiaman merumuskan hubungan dialogis antara normativitas dan historisitas al-Qur'an. ${ }^{37}$ Hal ini yang

\footnotetext{
${ }^{35}$ Fatwa, 1-7.

${ }^{36}$ Muhammad Fathoni, "Amm Dan Khass: Pengaruhnya Dalam Penafsiran Al-Qur'An," Kontemplasi: Jurnal Ilmu-Ilmu Ushuluddin 4, no. 2 (2016): 339.

${ }^{37}$ Supena, "Konstruksi Epistemologi Fikih Pandemik: Analisis Fatwa-Fatwa MUI,” 128.
} 
kemudian dalam diskursus studi Islam kontemporer telah dikenal dua pendekatan, yakni pendekatan normatif dan pendekatan historis. ${ }^{38}$

Berpijak pada uraian di atas, maka penekanan fatwa MUI terhadap ayat-ayat yang bersifauniversal ('am) menunjukkan landasan epistemologis fatwa MUI elastis dan fleksibel dalam memahami dan menjadikan nas al-Quran maupun Hadis sebagai dalil argumen.Interpretasi ayat-ayat universal oleh MUI sebagai argumentasi norma fatwa yang mengatur interaksi sosial di ruang medsos menunjukan bahwa MUI mengacu pada nilai etik sosial-universalyang termuat dalam ungkapanteks ayat berdasarkan kondisi sosio-historis danillat hukmnya yang kemudian diaktualisasikan sebagai nilai etik (norma) bermuamalah di medsos.

Kedua, kaidah-kaidahhukum Islam (qawaid fiqhiyah), antara lain.(1)al-aslu fi al-mu'amalati al-ibaakhatu illa an yadullu daliilun 'alaa al-takhriimi(pada dasarnya, segala bentuk muamalat diperbolehkan kecuali ada dalil yang mengharamkannya atau meniadakan kebolehannya). (2)dar'ual-mafaasid 'alaa jalbi al-mashoolikhi (menghindarkan mafsadat didahulukan atas mendatangkan maslahat). (3)al-dararu yuzalu (bahaya harus dihilangkan). (4) al-Kitaaabu kal khitoobi(tulisan itu memiliki kedudukan hukumseperti ucapan). (5)laa'ibrotu littawaahimi (waham hal yang masih hipotetik tidak bisa dijadikan pegangan). (6)tshorrufu al-imaami 'alaa alroo'iyyati manuuthun bi al-mashlakhati (kebijakan seorang pemimpin atas rakyat harus berdasarkan kemaslahatan). ${ }^{39}$

Berbagai kaidah hukum Islam yang menjadi dalil argumen fatwa MUI di atas menunjukan bahwa ketentuan normafatwa MUI terkait muamalah di medsos menekankan pada kaidahsadd al-zariah (tindakan preventif) ${ }^{40}$ dan maslahah mursalah (kemashlahatan umum). ${ }^{41}$

\footnotetext{
${ }^{38}$ Pendekatan normatif masih menekankan penghormatan nilai normatif dan pensakralan terhadap teks. Implikasikasi paradigmatiknya, yakni pemahaman terhadap ajaran Islam yang terdapat teks wahyu (nas) menjadi sangat legal-formal dan rigid.Hal demikian pada akhirnya dapat menyebabkan ragam keilmuan dan pemikiran Islam menjadi tidak solutif, bahkan dapat menjadi paradox dengan problem empiris dalam kehidupan sosial manusia. Sedangkan pendekatan historis lebih menekankan pada makna substansial yang terdapat di balik simbol dan teks-teks ajaran Islam. Implikasi paradigmatiknya, yakni perkembangan kajian atau pemikiran Islam senantiasa dapat progresif dan kompatibel dengan progresivitas kehidupan Meskipun tidak dipungkiri bahwa pendekatan historis ini sering mengalami kritikan karena diduga akan menjadikan Islam kehilangan autensitasnya. Nasitotul Janah, "Pendekatan Normativitas Dan Historisitas Serta Implikasinya Dalam Perkembangan Pemikiran Islam,” Cakrawala: Jurnal Studi Islam 13, no. 2 (2018): 102.

${ }^{39}$ Fatwa, Fatwa Majelis Ulama Indonesia (MUI) Nomor 24 Tahun 2017 Tentang Hukum dan Pedoman Bermuamalah Melalui Media Sosial, 6-7.

${ }^{40}$ Secara etimologis, term Sadd al-dzari'ah terdiri dari dua kata yakni sadd dan dzari'ah. Sadd berarti penghalang, hambatan atau sumbatan.Sementara itu, dzari'ah berarti jalan (medium).Sedangkan makna terminologisnya, yakni upaya mengahalangi atau menghindarkanberbagai hal yang dapat mengantarkan manusia padahal yang dilarang (bahaya).Moh Bahrudin, Ilmu Ushul Fiqh (Bandar Lampung: Aura, 2019), 72.

${ }^{41}$ Maslahat mursalah merupakan pemikiran hukum Islam yang menjadikanmaslahah (kepentingan atau kebutuhan manusia) yang bersifat tidak terikat (mursalah) sebagai sumber atau dasar penetapan hukum Islam. Konsep inijuga dikenal dengan sebutan istislâh atau al-masâlih almursalah.Muhammad Rusfi, Hukum Kebiri Dalam Perspektif Maqasid Al-Syariah Dalam Hukum Kebiri Dalam Kajian Interdisipliner (Surabaya: CV. Gemilang, 2018), 69.
} 
Penekanan fatwa MUI terhadap kaidahsadd al-zari'ahdalam mengatur interaksi sosial (muamalah) merupakan hal yang tepat. Mengingat keberadaansadd al dzari'ahdapat menjadi basis epistemologis penetapan normafatwa yangfleksibel dalam merespons dinamika problematikahokum atas perubahan sosial masyarakat yang dinamis.Di mana melalui kaidah sadd al dzari ah diharapkan dapat melahirkan norma hukum Islamyang mendudukkan persoalan hukum secara proporsional dengan menekankan aspek kemanfaatan dan kemaslahatan bagi kehidupan sosial masyarakat. ${ }^{42}$ Sedangkan penekanan kaidah maslahah mursalah (kemashlahatan umum) menunjukan bahwa basis paradigmatik norma dalam Fatwa MUIbermuara pada terwujudnya kemaslahatan universal dalam kehidupan interaksi sosial. Pernyataan demikian tidaklah berlebihan. Mengingat keberadaan kaidah maslahah mursalah merupakan dalil independen yang menduduki posisi kuat sebagai basis epistemologis dalam penetapan hukum, karena tidak membutuhkan justifikasi dari teks wahyu (nas), baik yang mendukungnya maupun yang menolaknya. ${ }^{43}$

Ketiga, pendapat ulama klasik.Pendapat para ulama yang menjadi bagian argument fatwa MUI terkait muamalah di medsos, antara lain.(1) Pendapat Al-Imam An-Nawawi dalam Kitab Syarh Shahih Muslim terkait sikap merespons penyebaran berita yang datang (2) Pendapat Imam al-Qurthuby dalam kitab Tafsir Al-Qurtubi dalam menafsirkan ayat al-Quran terkait ghibah (3) Pendapat Imam al-Shan'ani dalam kitab Subulus Salam juz 4 halaman 188.(4) Pendapat Imam al-Nawawi dalam kitab Riyadlu al-Shalihin tentang pengecualian kebolehan ghibah. ${ }^{44}$

Keberadaan berbagai pendapat para ulama klasikdi atas menunjukan bahwa MUI masih tetap mempertahakan kontinuitas dalam sejarah tradisi pemikiran Islam klasik sebagai basis paradigmatik dalam merespons isu-isu kontemporer.Dalam hal ini, yakni isu terkait penggunaan medsos sebgai medium interaksi sosial di era modern saat ini.Pertimbangan argumentatif Fatwa MUI tersebut patut untuk diapresiasi.Hal demikian disebabkan secara sosiologis, pemikiranIslam klasik menjadi warisan berharga yang dapat menjadi landasan paradigma umat Islam dalam memecahkan problem sosial yang dinamis.Namun hal tersebut tetaptetap disertai dengan sikap kritis-analitik. ${ }^{45}$ Atas dasar inilah dapat dikatakan bahwa upaya memlihara kontinuitas tradisi khasanah pemikiran Islam klasik sebagai bagian argument norma Fatwa menunjukkan bahwa MUI tidak sekedaringin mengedepankan validitas normative teologis dalam konstruksi epistemologisnya, melainkan jugaberupaya untuk menghormati dan menjaga pemikiran dan praktik sosiologis keberagamaanumat Islam Indonesia yang didominasi oleh pemikiran madzhab Syafi. ${ }^{46}$

\footnotetext{
${ }^{42}$ Ali Imron, "Menerapkan Hukum Islam Yang Inovatif Dengan Metode Sadd Al Dzari'ah," QISTIE 4, no. 1 (2010): 65.

${ }^{43}$ Asriaty Asriaty, "Asriaty, "Penerapan Mashlahah Mursalah Dalam Isu-Isu Kontemporer," Madania: Jurnal Kajian Keislaman 19, no. 1 (2015): 127-28.

${ }^{44}$ Fatwa, Fatwa Majelis Ulama Indonesia (MUI) Nomor 24 Tahun 2017 Tentang Hukum dan Pedoman Bermuamalah Melalui Media Sosial, 8-10.

${ }^{45}$ Mutohharun Jinan, "Kontribusi Keilmuan Islam Klasik Dalam Perkembangan Islam Kontemporer: Perspektif Epistemologis," 2016, 82.

${ }^{46}$ Corak pemikiran Islam rmazhab Syafìi yang sejalan dengan kepribadian masyarakat Indonesia telah menjadikannya sebagai mazhabyang masih senantiasadipraktikan di tengah
} 
Keempat,pendapat para ahli terkait penggunaan media sosial.Dalam pertimbangan ini yang digunakan, antara lain. (1) Paparan Menteri Komunikasi dan Informatika Republik Indonesia (RI) tentang pentingnya peran masyarakat dalam membangun literasi dalam pemanfaatan media digital (2)Penjelasan Dirjen Aptika Kominfo RI serta penjelasan Ahli dan Praktisi Media Digital Nu'man Luthfi dan Teddy Sukardi tentang peta masalah di dunia digital, problematika dan berbagai strategi yang diambil serta pentingnya keterlibatan seluruh masyarakat dalam mendukung pemanfaatan media sosial untuk kemaslahatan dan mencegah dampak negatif yang ditimbulkan.

Keterlibatan pandangan para ahli terkait penggunaan medsos di atas dalam bagian landasan argumentas Fatwa MUI menunjukan bentuk integrasi pemikiran hukum Islam yang dimotori oleh para ulama MUI dengan pandangan ilmuan. Upaya integrasi tersebutdapat dikatakan sebagai bentuk integrasi anatara Islam dan sains dalam ranah epistemologi. Apa yang dilakukan MUI ini dapat dikatakan sebagai bentuk pengejawantahan dari paradigma interkoneksitas antara agama dan sains. Menurut Amin Abdullah, paradigma interkoneksitas seharusnya dapat memberikan pandangan dunia (world view) bahwa manusia dalam menjalankan tugasnya di muka bumi hendaknya memiliki sifat terbuka, saling kerjasama, transparan, bertanggungjawab serta mampu menghidupkan diskusi ilmiah ${ }^{47}$

Uraian di atas memperlihatkan bahwa MUI berupaya untuk mengilangkan paradigma dikotomik yang memisahkan antara ajaran agama dengan sains dalam merespons problematika sosial umat. Apa yang dilakukan MUI tersebut juga dapat disebut dengan istilah teologisasi sains melalui pola interanneal, yakni relasi saling menguatkan. Maksudnya,agama mendorong untuk merealisasikan kajian ilmiah tentang alam berikut fenomenanya. Sementara itu, sains dan teknologi menguatkan keimanan dan memudahkan manusia dalam menjalankan tugasnya di muka bumi. ${ }^{48}$

\section{Simpulan}

Berpijak pada uraian pembahasan inti dalam penelitian ini dapat disimpulkan bahwa konstruksi epistemologis hokum Islam dalam fatwa MUI tentang Hukum dan Pedoman Bermumalah Melalu Media Sosial mengintegrasikan kecenderungan paradigma idealisme dan realisme hukum Islam.Kesimpulan besar demikian dapat dilihat dari berbagai unsure yang melandasi kostruksi bagunan epistemologis Fatwa MUI tersebut. Pertama,nilai moral etik universal('am) yang diambil dari landasan teks teologis (nas). Kedua,penggunaan kaidah-kaidah hukum Islam (qawaid

kehidupan keberagamaan umat Islam Indonesia. Di samping itu, peran aktif para ulama yang bermazhab Syafìi dalam upaya penyebaran mazhab Syafìi dilakukan melalui berbagai media, antara lain, jalur pendidikan, dakwah, kesenian dan Organisasi Masyarakat Islam dalam merumuskan berbagai norma atau fatawa hukum Islam dalam merespons problem yang dihadapi oleh umat Islam di Indonesia. Anny Nailatur Rohmah and Ashif Az Zafi, "Jejak Eksistensi Mazhab Syafii Di Indonesia,” Tamaddun: Jurnal Sejarah Dan Kebudayaan Islam 8 (2020): 190.

47 Muhammad Amin Abdullah, "Islamic Studies Di Perguruan Tinggi: Pendekatan Integratif-Interkonektif, Yogyakarta: Pustaka Pelajar, 2010," Abu Zayd, Nashr Hamid and Esther R Nelson, Voice of an Exile: Reflections on Islam, London: Preager, 2004, iiv-ix.

${ }^{48}$ Hasan Basri, "Teologi Sains: Mengatasi Dikotomi Sains-Agama Perspekif Islam,” Jurnal Pemikiran Islam 5, no. 2 (2019): 377. 
fiqhiyah) yang menekankan pada kaidahsadd al-zari'ah (tindakan preventif) dan maslahah mursalah (kemashlahatan umum).Ketiga,pendapat ulama klasik.Keempat,penjelasan ilmuan pendapat para ahli terkait penggunaan media sosial.Temuan penelitian ini menunjukan landasan epistemologi hukum Islam dalam merumuskan Fatwa terkait mumalah di medsos bukanlah landasan yang hanya bersifat normatif-deduktif, melaindakan juga empirik-induktif

\section{DAFTAR PUSTAKA}

Abdullah, Muhammad Amin. "Islamic Studies Di Perguruan Tinggi: Pendekatan Integratif-Interkonektif, Yogyakarta: Pustaka Pelajar, 2010.” Abu Zayd, Nashr Hamid and Esther $R$ Nelson, Voice of an Exile: Reflections on Islam, London: Preager, 2004.

Akram, Waseem, and Rekesh Kumar. "A Study on Positive and Negative Effects of Social Media on Society." International Journal of Computer Sciences and Engineering 5, no. 10 (2017): 351-54.

Alyusi, Shiefti Dyah. Media sosial : Interaksi, Identitas dan Modal Sosial. Prenada Media, 2019.

Anwar, Fahmi. "Perubahan Dan Permasalahan Media Sosial." Jurnal Muara Ilmu Sosial, Humaniora, Dan Seni 1, no. 1 (2017): 137-44.

Asriaty, Asriaty. "Asriaty, "Penerapan Mashlahah Mursalah Dalam Isu-Isu Kontemporer.” Madania: Jurnal Kajian Keislaman 19, no. 1 (2015).

Bahrudin, Moh. Ilmu Ushul Fiqh. Bandar Lampung: Aura, 2019.

Basri, Hasan. “Teologi Sains: Mengatasi Dikotomi Sains-Agama Perspekif Islam.” Jurnal Pemikiran Islam 5, no. 2 (2019).

Christiany, Juditha. "Interaksi Komunikasi Hoax Di Media Sosial Serta Antisipasinya." Jurnal Pekommas 3, no. 1 (2018).

Dewi, Maya Sandra Rosita. "Islam Dan Etika Bermedia (Kajian Etika Komunikasi Netizen Di Media Sosial Instagram Dalam Perspektif Islam).” Research Fair Unisri 3, no. 1 (2019).

Fathoni, Muhammad. "Amm Dan Khass: Pengaruhnya Dalam Penafsiran AlQur'An.” Kontemplasi: Jurnal Ilmu-Ilmu Ushuluddin 4, no. 2 (2016): 337-62.

Fatwa, Komisi. Fatwa Majelis Ulama Indonesia (MUI) Nomor 24 Tahun 2017 Tentang Hukum dan Pedoman Bermuamalah Melalui Media Sosial (n.d.). Accessed August 14, 2021.

Hadikusuma, Wira. "Epistemologi Bayani, Irfani Dan Burhani Al-Jabiri Dan Relevansinya Bagi Studi Agama Untuk Resolusi Konflik Dan Peacebuilding." Jurnal Ilmiah Syi'ar 18, no. 1 (2018).

Harahap, Ikhwanuddin. "Pendekatan Al-Mașlaḥah Dalam Fatwa Majelis Ulama Indonesia (Mui) Nomor 24 Tahun 2017 Tentang Hukum Dan Pedoman Bermuamalah Melalui Media Sosial.” Yurisprudentia: Jurnal Hukum Ekonomi 3, no. 1 (2017): 47-65.

Imron, Ali. "Menerapkan Hukum Islam Yang Inovatif Dengan Metode Sadd Al Dzari'ah." QISTIE 4, no. 1 (2010). 
Islamy, Athoillah. "Fatwa About Social Interaction On Social Media In The Paradigm Of Islamic Legal Philosophy.” Al-Mishbah: Jurnal Ilmu Dakwah Dan Komunikasi 15, no. 2 (2020): 163-74.

- - - "Landasan Filosofis Dan Corak Pendekatan Abdurrahman Wahid Tentang Implementasi Hukum Islam Di Indonesia." Al-Adalah: Jurnal Hukum Dan Politik Islam 6, no. 1 (2021): 51-73.

_-_. "Paradigma Sosial Profetik Dalam Bermuamalah Di Media Sosial." Tadbir: Jurnal Manajemen Dakwah FDIK IAIN Padangsidimpuan 3, no. 1 (2021): 83104.

-_- "Pemikiran Hukum Islam Nurcholish Madjid." Disertasi Pascasarjana Universitas Islam Negeri Walisongo, 2021.

Istiani, Nurul, and Athoillah Islamy. "Fikih Media Sosial Di Indonesia (Studi Analisis Falsafah Hukum Islam Dalam Kode Etik NetizMu Muhammadiyah).” ASY SYAR'IYYAH: JURNAL ILMU SYARI'AH DAN PERBANKAN ISLAM 5, no. 2 (2020): 202-25.

Janah, Nasitotul. "Pendekatan Normativitas Dan Historisitas Serta Implikasinya Dalam Perkembangan Pemikiran Islam.” Cakrawala: Jurnal Studi Islam 13, no. 2 (2018): 102-19.

Jayus, Muhammad, and Muhammad Irham. "Fiqh Rasional Dan Tekstual Ibn Rusyd Serta Implikasinya Dalam Hukum Islam Modern.” El-Izdiwaj: Indonesian Journal of Civil and Islamic Family Law, 1, no. 1 (2020).

Jinan, Mutohharun. "Kontribusi Keilmuan Islam Klasik Dalam Perkembangan Islam Kontemporer: Perspektif Epistemologis," 2016.

Mastori, Mastori, and Athoillah Islamy. "Menggagas Etika Dakwah Di Ruang Media Sosial." KOMUNIKASIA: Journal of Islamic Communication and Broadcasting 1, no. 1 (2021): 1-18.

Moleong, Lexy J. "Metodologi Penelitian Kualitatif Edisi Revisi.” Bandung: PT Remaja Rosdakarya 103 (2007).

Nasrullah, Rulli. Teori Dan Riset Media Siber (Cybermedia). Kencana, 2016.

Ningrum, Dian Junita, Suryadi Suryadi, and Dian Eka Chandra Wardhana. "Kajian Ujaran Kebencian Di Media Sosial.” Jurnal Ilmiah Korpus 2, no. 3 (2018): 24152.

Nurcholis, Moch. "Integrasi Islam Dan Sains: Sebuah Telaah Epistemologi." FALASIFA: Jurnal Studi Keislaman 12, no. 1 (2021): 116-34.

"Perludem. 19 Mei 2020. Https://Perludem.Org/Wp-Conten - Penelusuran Google." Accessed August 23, 2020..

Rohmah, Anny Nailatur, and Ashif Az Zafi. "Jejak Eksistensi Mazhab Syafii Di Indonesia.” Tamaddun: Jurnal Sejarah Dan Kebudayaan Islam 8 (2020).

Rusfi, Muhammad. Hukum Kebiri Dalam Perspektif Maqasid Al-Syariah Dalam Hukum Kebiri Dalam Kajian Interdisipliner. Surabaya: CV. Gemilang, 2018.

Setiawan, Radita, and Muhammad Okky Arista. "Efektivitas Undang-Undang Informasi Dan Transaksi Elektronik Di Indonesia Dalam Aspek Hukum Pidana." Jurnal Hukum Pidana Dan Penanggulangan Kejahatan 2, no. 2 (2013).

Supena, Ilyas. "Konstruksi Epistemologi Fikih Pandemik: Analisis Fatwa-Fatwa MUI." A L-Manāhij: Jurnal Kajian Hukum Islam 15, no. 1 (2021). 
Suyati, Suyati. “Dampak Media Sosial Terhadap Konflik Di Masyarakat.” JURNAL PETIK 7, no. 1 (2021): 30-36.

Syarief, Fauzi. "Pemanfaatan Media Sosial Dalam Proses Pembentukan Opini Publik (Analisa Wacana Twitter Sby)." Jurnal Komunikasi 8, no. 3 (2017).

Umar, Subehan Khalik. "Studi Kritis Terhadap Respon Majelis Ulama Indonesia (Mui) Tentang Pemanfaatan Media Sosial Dalam Bermuamalah.” Al Daulah: Jurnal Hukum Pidana Dan Ketatanegaraan 7, no. 1 (2018): 39-50.

Wahyudin, Uud. "Kismiyati El Karimah. 2016.'Etika Komunikasi Di Media Sosial,."' In Prosiding Seminar Nasional Komunikasi, n.d. 